\title{
A LOW-COST PRINTED CIRCUIT BOARD DESIGN TECHNIQUE AND PROCESSES USING FERRIC CHLORIDE SOLUTION
}

\author{
C. T. Obe ${ }^{1}$, S. E. Oti ${ }^{2}$, C. U. Eya ${ }^{3, *}$, D. B. N. Nnadi ${ }^{4}$ and O. E. Nnadi ${ }^{5}$

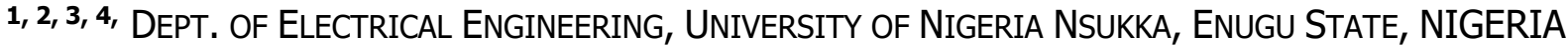 \\ 5, EnUgu Electricity Distribution Co. (EEDC), 62 OKPARA AVEnUe ENugu, ENUGu State, NIGERIA \\ E-mail addresses: ${ }^{1}$ chinedu.obe@unn.edu.ng , ${ }^{2}$ stephen.oti@unn.edu.ng, ${ }^{3}$ candidus.eya@unn.edu.ng, \\ 4 damian.nnadi@unn.edu.ng,5olivennadi@gmail.com
}

\begin{abstract}
This paper presents a low-cost printed circuit board (PCB) design technique and processes using ferric chloride ( $\mathrm{FeCl}_{3}$ ) solution on a metal plate for a design topology. The PCB design makes a laboratory prototype easier by reducing the work piece size, eliminating the ambiguous connecting wires and breadboards circuit errors. This is done by manual etching of the designed metal plate via immersion in ferric chloride solutions for a given time interval 0-15mins. With easy steps, it is described on how to make a conventional single-sided printed circuit board with low-cost, time savings and reduced energy from debugging. The simulation and results of the printed circuit is designed and verified in the Multisim software version 14.0 and LeCroy WJ35A oscilloscope respectively.
\end{abstract}

Keywords: Etching, Ferric Chloride, Insertion, Multisim, Metal Plate, Printed Circuit Board.

\section{INTRODUCTION}

Globally, people are constantly looking for new ways of doing their conventional task with ease, reduced cost and increased efficiency. Printed circuit boards are electronic circuits created for mounting electronic components on a nonconductive board after creating conductive connections between the respective components that needed to be linked up. Because PCBs are the most essential part in an electronic system, these are employed in the manufacturing of business machines and computers, as well as telecommunication circuitries, control panels, and home entertainment equipment [1].

PCB design goes through software and hardware processes. The software part entails the use of a given software like Multisim, Eagle, Proteus, KiCad, EasyEDA etc. to design the printed circuit prototype while the hardware part is the mechanical transfer, etching, drilling and soldering of the components within the scope of the design. The material used is a foil clad having the front side as metal while the back side is non-metal. The manufacturing process of PCB takes a few hours and sometimes requires that several of the steps be repeated to complete the process since the manufacture of printed circuit boards involves both the addition and removal of materials via mechanical, electrical, or chemical tactic [2]. The pre-designed tracks reduce the wiring, thereby reducing the faults arising from loosed connections and short circuiting. At the end, one simply needed to place the components on the PCB design and solder them. There are four varieties of printed circuit boards: single-sided, double-sided, multi-layered, and flexible boards [3]. The PCB types were determined by density, spatial requirements and complexity of the circuits therein. A single-sided board was made from rigid laminate consisting of a woven glass epoxy base material clad with copper on one side of the base material with varying thickness whereas double-sided board is made from the same type of base material clad with copper on two sides of the base material with varying thickness. Multi-layer boards which allow for increased complexity and density were manufactured in the same way as single and 
double-sided boards, except that conducting circuits were etched on both the external and internal layers [4]. A flexible PCB is a printed circuit produced on a flexible substrate, allowing it to be folded or bent to fit the available space or allow relative movement.

\section{THE FERRIC CHLORIDE (IRON III CHLORIDE, $\mathrm{FeCl}_{3}$ )}

Iron (III) Chloride $\left(\mathrm{FeCl}_{3}\right)$ is an inorganic compound and is also known as Ferric Chloride (Iron trichloride). It is a common compound of Iron in the +3 -oxidation state. The anhydrous compound is a crystalline solid with a melting point of $307.6^{\circ} \mathrm{C}$ [5]. The colour depends on the viewing angle: by reflected light the crystals appear dark green, but by transmitted light they appear purple-red.

Fig. 1 shows a yellowish crystals type of Iron III Chloride, but Fig. 2 appeared dark green of the same crystal type of the Iron III Chloride, whereas, Fig. 3 displayed the brown acidic solution of the Iron III Chloride in test tube.

When opened to the atmosphere, it attracts the atmospheric moisture as a result of being a hygroscopic substance. Therefore, it is necessary to keep away from atmospheric exposure until the time of usage. It is also important to keep away from any metallic surface when exposed to moisture to avoid immediate damage since it rapidly attacks metals on exposure to atmosphere.

\section{METHODOLOGY}

\subsection{The Circuit Schematic Software Design}

Before PCB lay-out is done, it is necessary to design a complete and accurate schematic diagram. A PCB design is a replica of one's schematic diagram drawn via any of the above-named software. If the schematic is neat, logical and clearly laid out, then the PCB design and implementation will be easier. Similarly, if the electric circuit outlines were drawn correctly, the laid-out PCB designer will not experience loss of signals after design. Little notes on the schematic that aid in the layout were also useful as to avoid critical guess. The schematic should be drawn with the PCB design in mind not only to remind the designer when it comes to laying out the board but they were useful for people reviewing the design. It is outside the scope of this paper to go into details on good schematic design, as it would require a complete article on its own. For instance, the pin that requires a guard track to any signal makes it clear to the designer laying out the board what precautions must be taken. A schematic topology for a $\pm 15 \mathrm{~V}$ power supply circuit in basic electronics is shown in Fig.4.

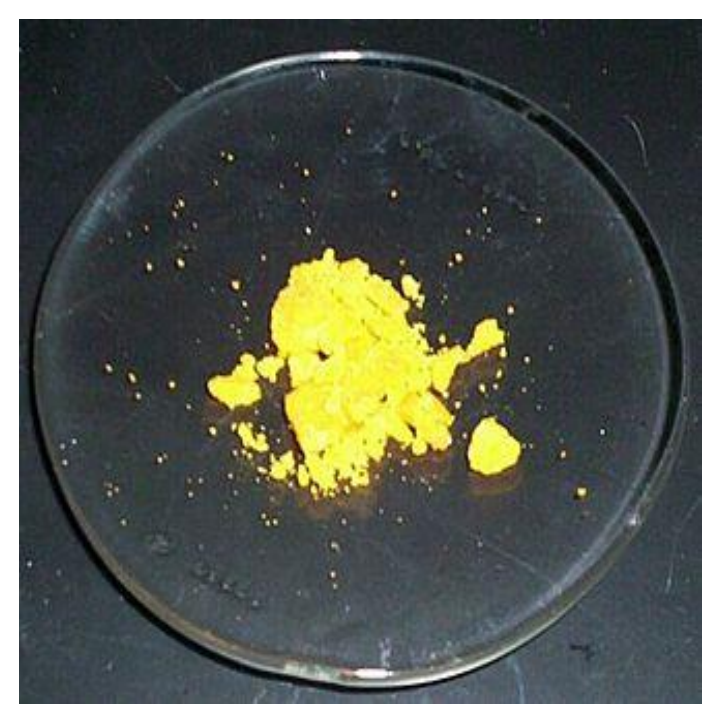

Fig.1: Iron III Chloride Hydrate

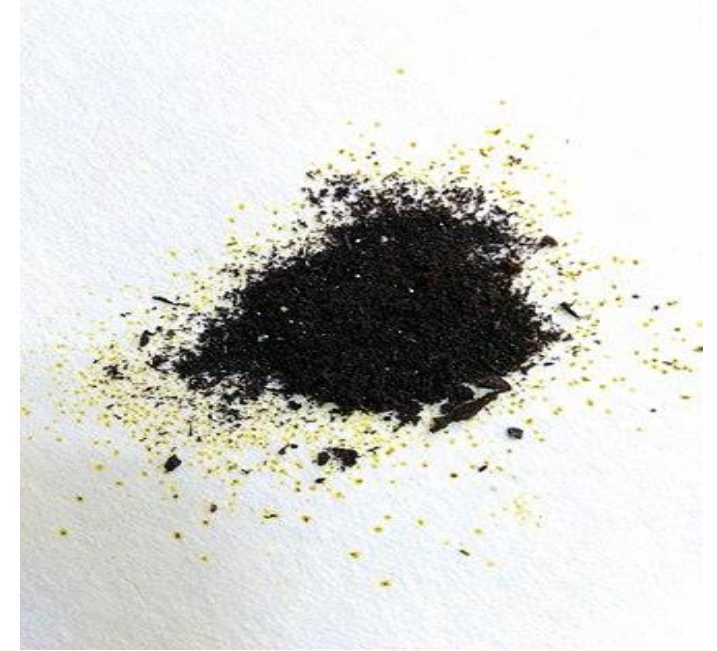

Fig.2: Iron III Chloride Anhydrous

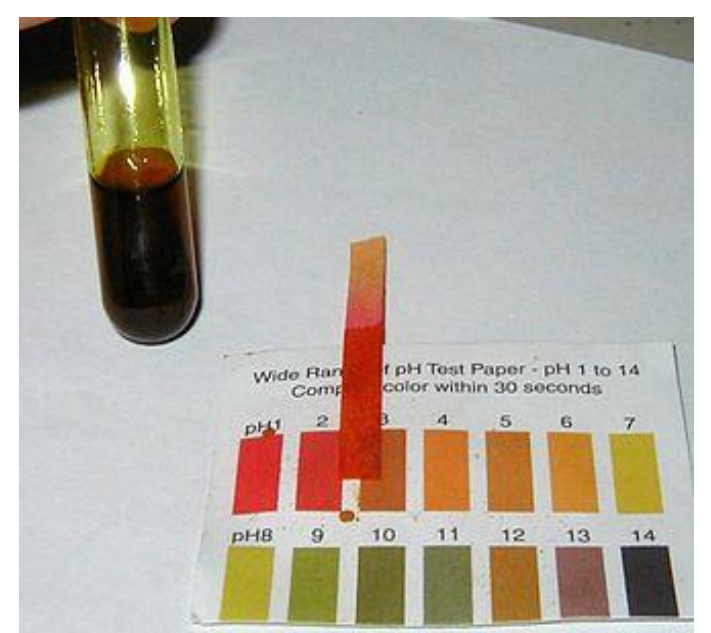

Fig.3: Iron III Chloride solution test 


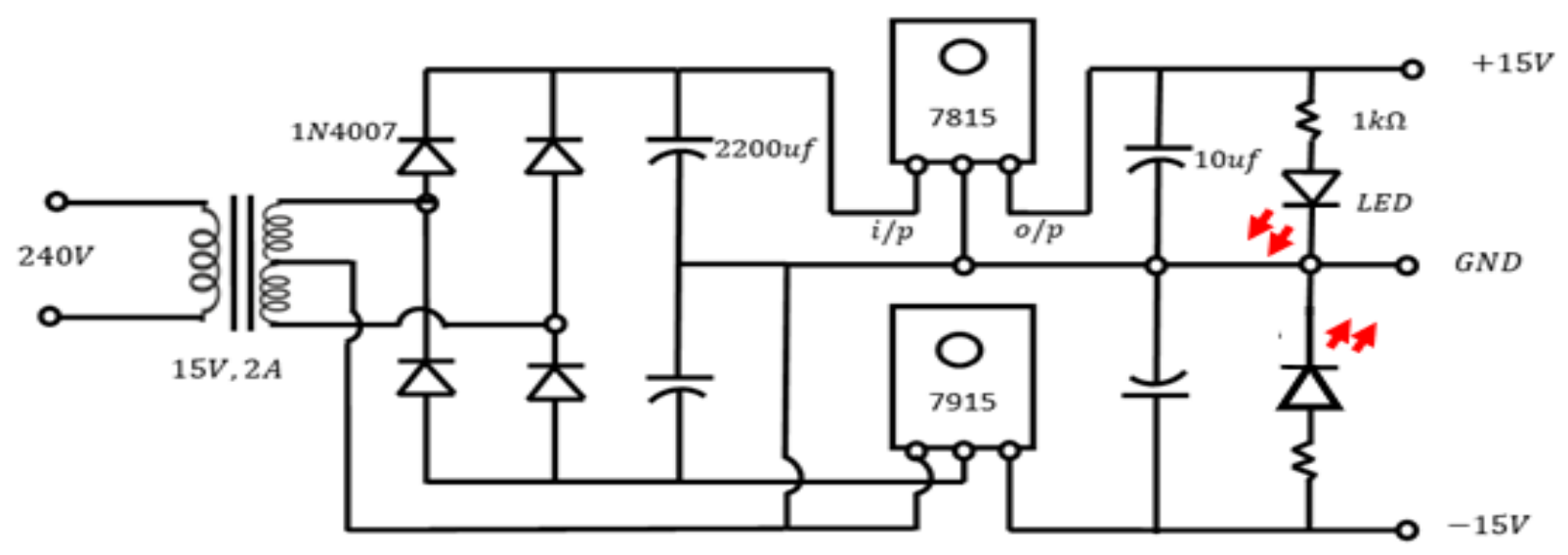

Fig.4: PCB power supply circuit prototype of $\pm 15 \mathrm{~V}$

In the Multisim file, the circuit drawing is done by picking and placing the components and then using the wire tool to interconnect them appropriately. The diagram was shown in Fig.5. After the assembly, a test run simulation was made with result shown in scope to ensure that the connection made were appropriate. The circuit auto-router is shown on the toolbar to the left-hand side of the screen were the line command is made.

After completing the drawing test, the schematic was then commanded to enter into ULTIBOARD scheme in another program window where $\mathrm{PCB}$ copper bottom lines and the actual (practical) size of the components were made. The diagram that represented that action was shown in Fig. 6 .

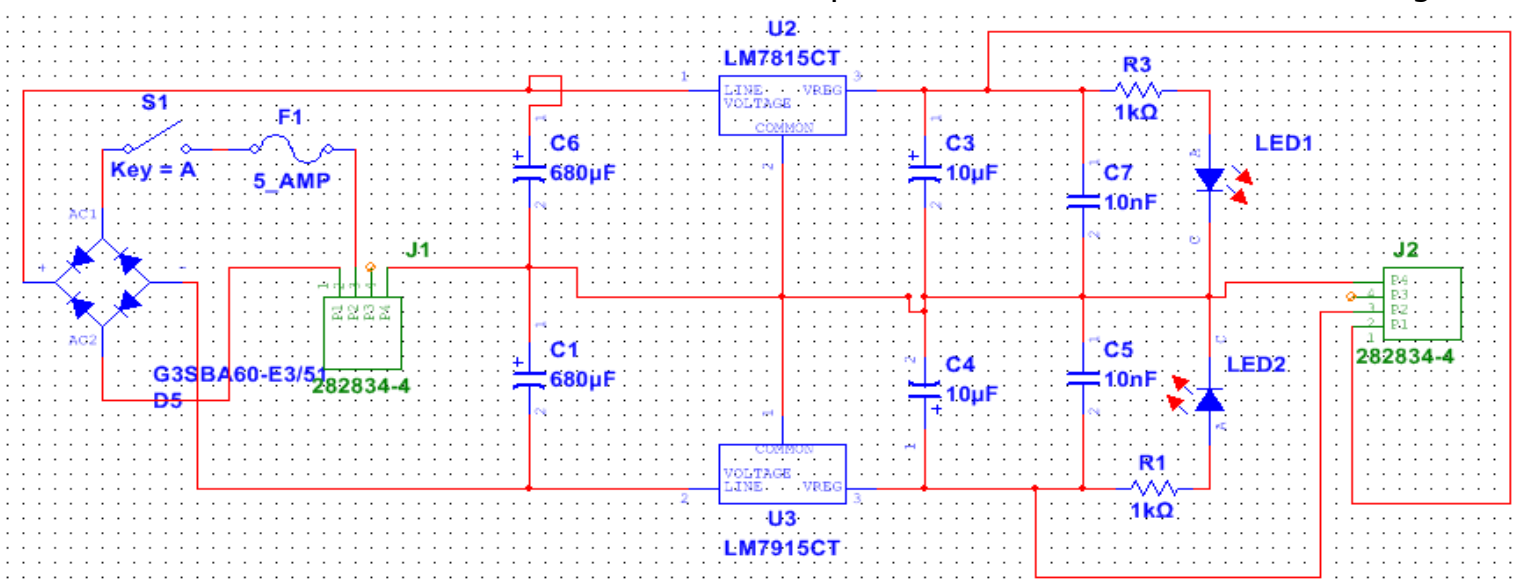

Fig.5: PCB schematic power supply circuit components in Multisim environment

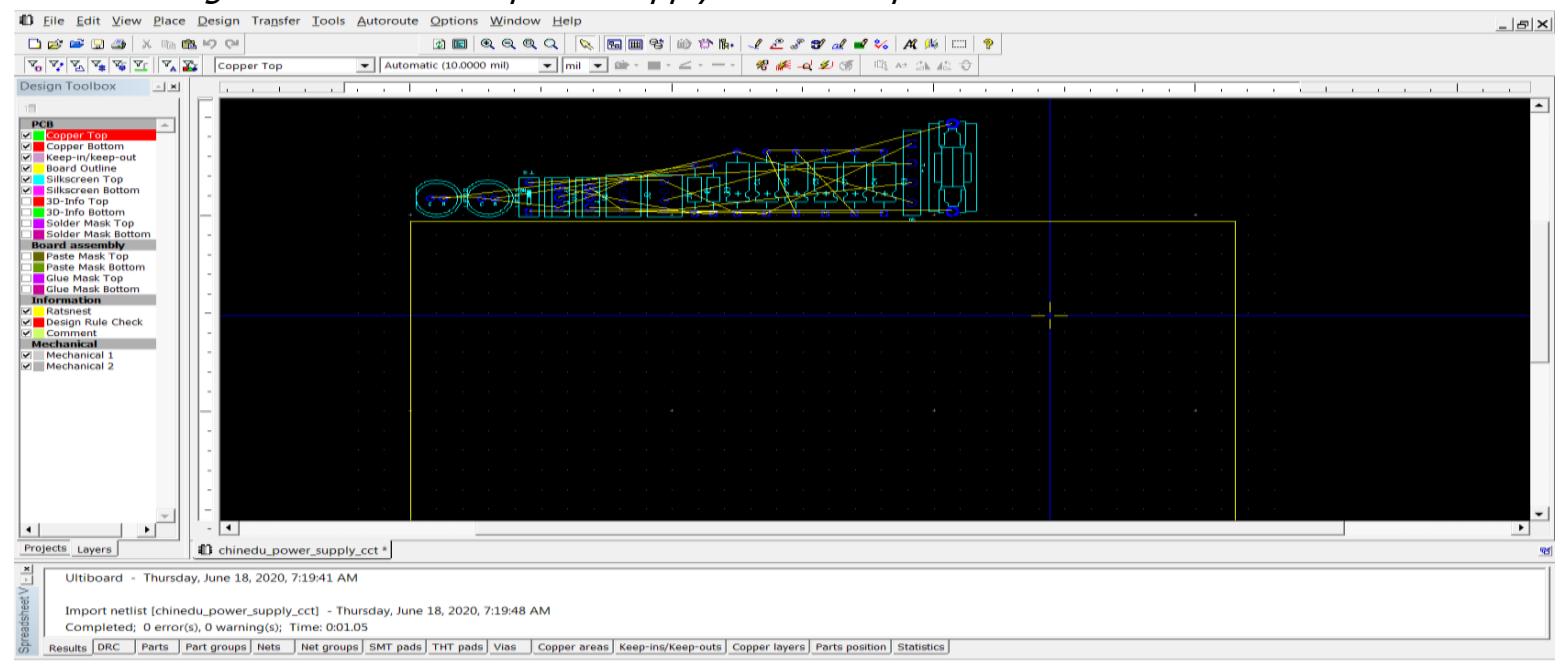

Fig.6: PCB schematic gross network lines transferred to Ulti-board in Multisim environment 
A finished components per circuit line connection with thick line-width measurement of $0.5 \mathrm{~mm}$ was shown in Figure 8. Figure 8 gave a rear-preview of how the PCB outline of Figure 5 looks like. It is necessary to crosscheck whether there was any short-circuit, thus gave room for correction(s).
A command prompt was made to drag the lump circuit to the rectangular sized board shown in Fig. 7 in order to meet the designed specification when readjusted. At this point, it is necessary to note that the program binds each component to its network connection (lines) irrespective of its location in the board.

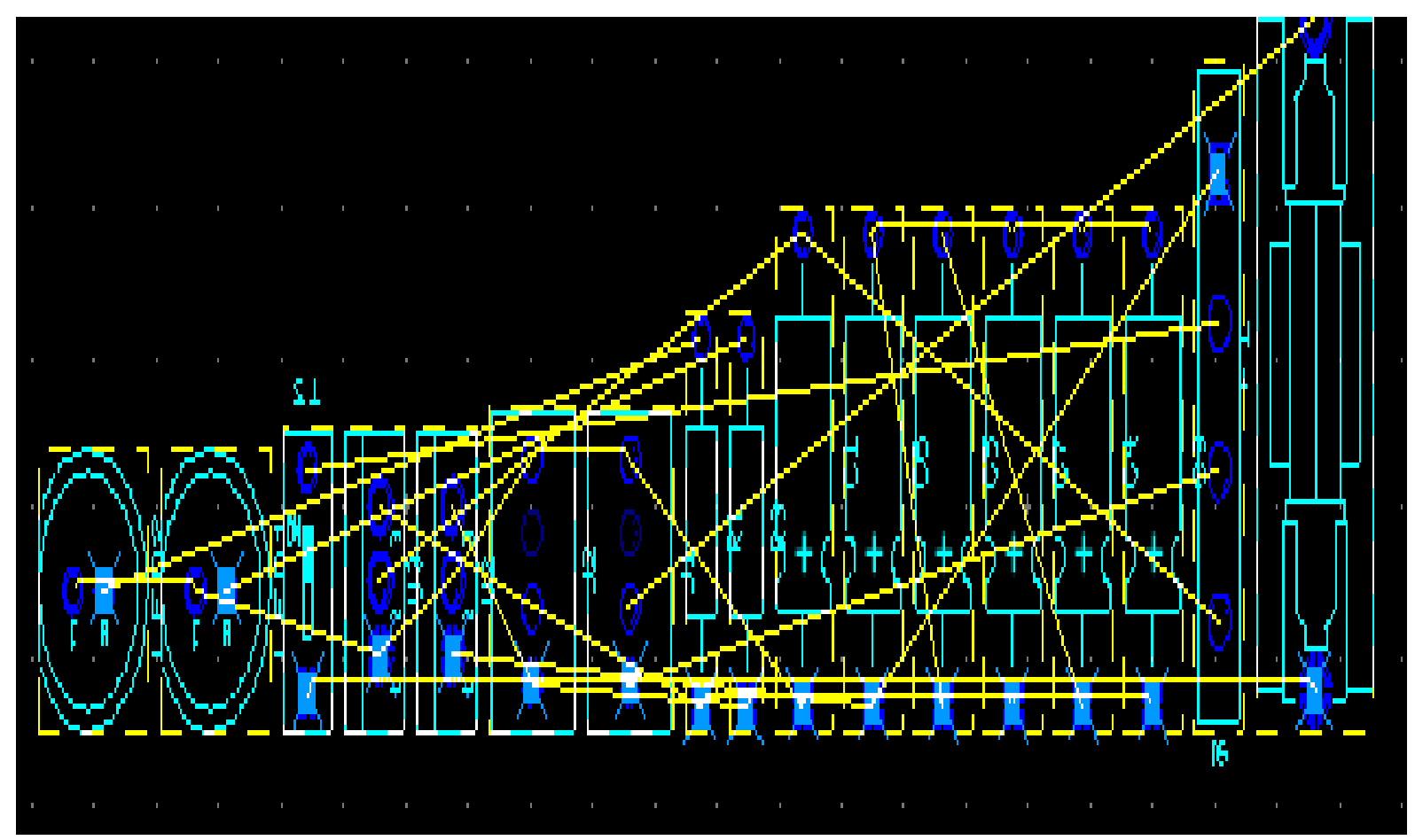

Figure 7: The PCB transferred to the Ulti-board layout pitch in Multisim environment.

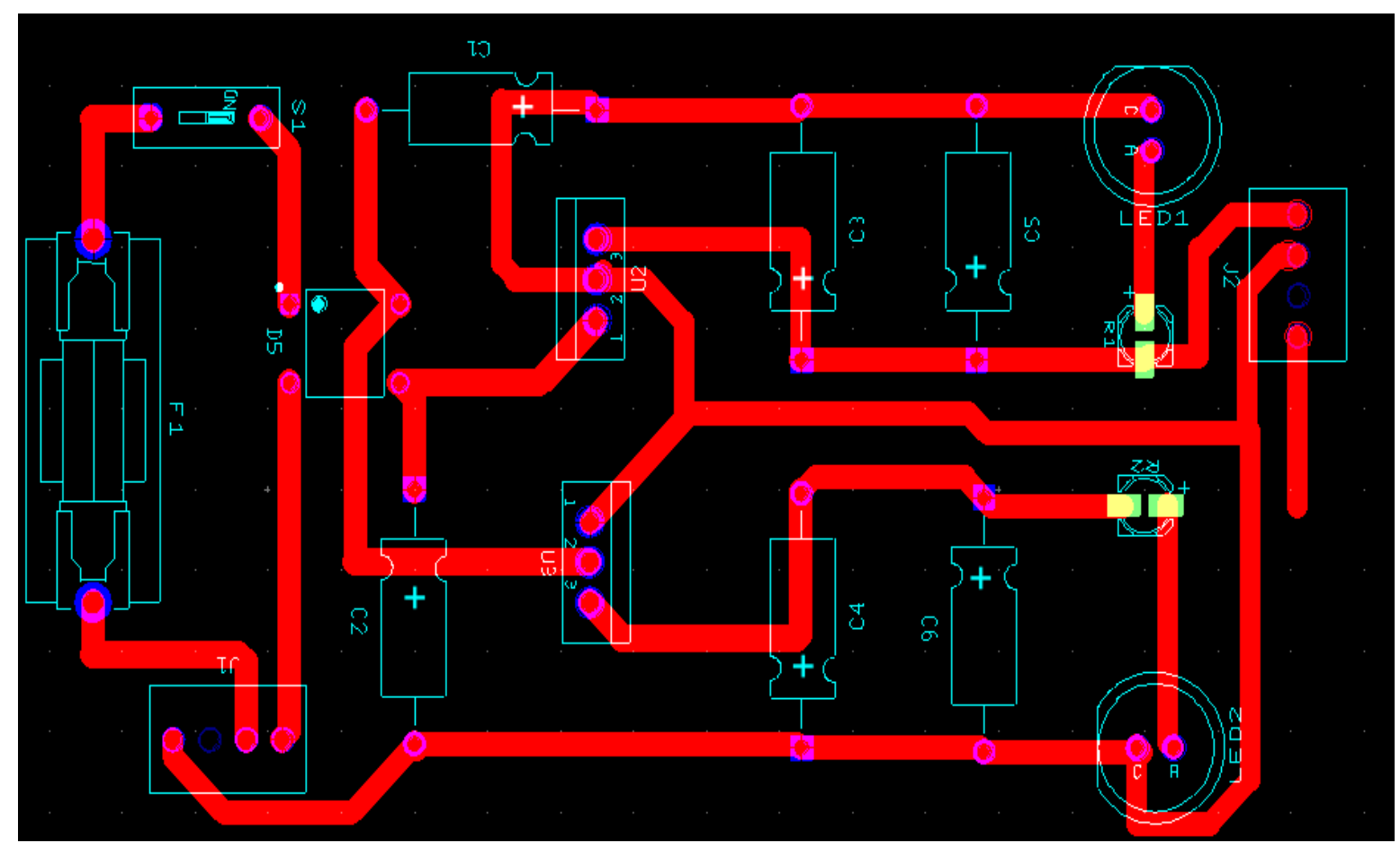

Fig. 8: PCB network lines and components properly drawn and positioned appropriately. 
The PCB design done in the Multisim Ulti-board environment was finally previewed in $3 \mathrm{D}$ as shown in Fig.9. Here, the preview was ready to be printed out on art paper which went into the metallic sheet prototype for the process of heat transfer. When printed, the white lined turned to black while the other plane parts of the paper sheet turn to white thereby making it easy to detect and transfer the circuit lines.

\subsection{The Method of PCB Hardware Design}

The steps for mechanical process of PCB design was shown in block diagram of Fig.10. From the circuit schematic, the metallic copper plate prototype was cut to the measured size. The printing and photo transfer entail the use of art paper to transfer the software designed 3D workpiece by the process of photo printing. The solder masking was the face to face dabbing of the printed work piece and the metal surface by the use of Tina fluid in order to stick the black ink lines to the metallic board. The next stage is to test for short-circuit and effect correction were necessary. The mechanical etching was done from the steps outlined in section 3.3. The washing and drying section was the used of water to remove the stickled paper from the board for a period of time when exposed to sunlight. Thereafter, the use of drilling machine (Fig.13) was used create a hole for the pin of the designed components. Soldering is done using led wire and soldering iron, observing soldering precautions. As a final precaution, a technician needs to perform electrical testing of the PCB design and mount appropriately.

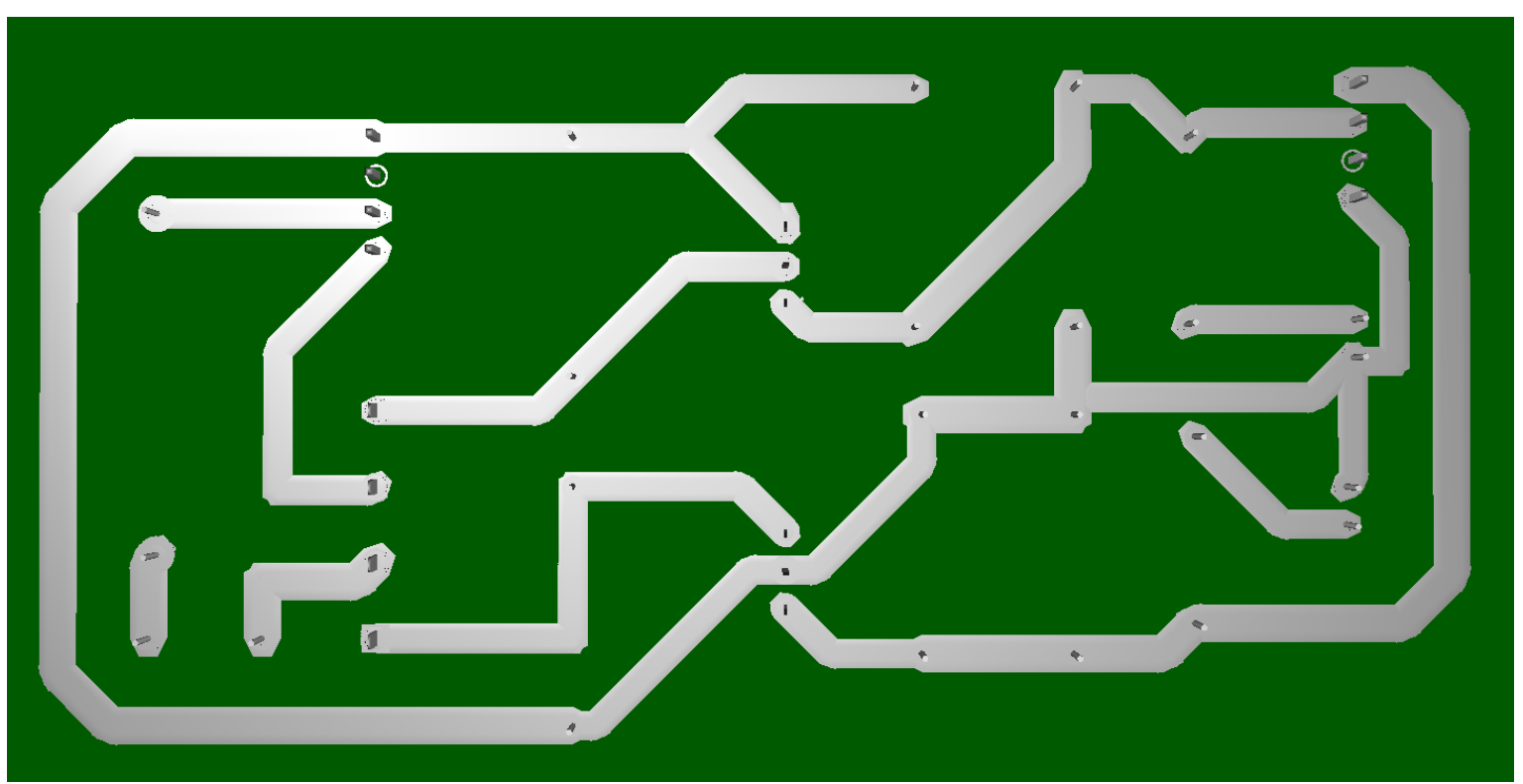

Fig.9: The PCB prototype viewed in 3D format before etching

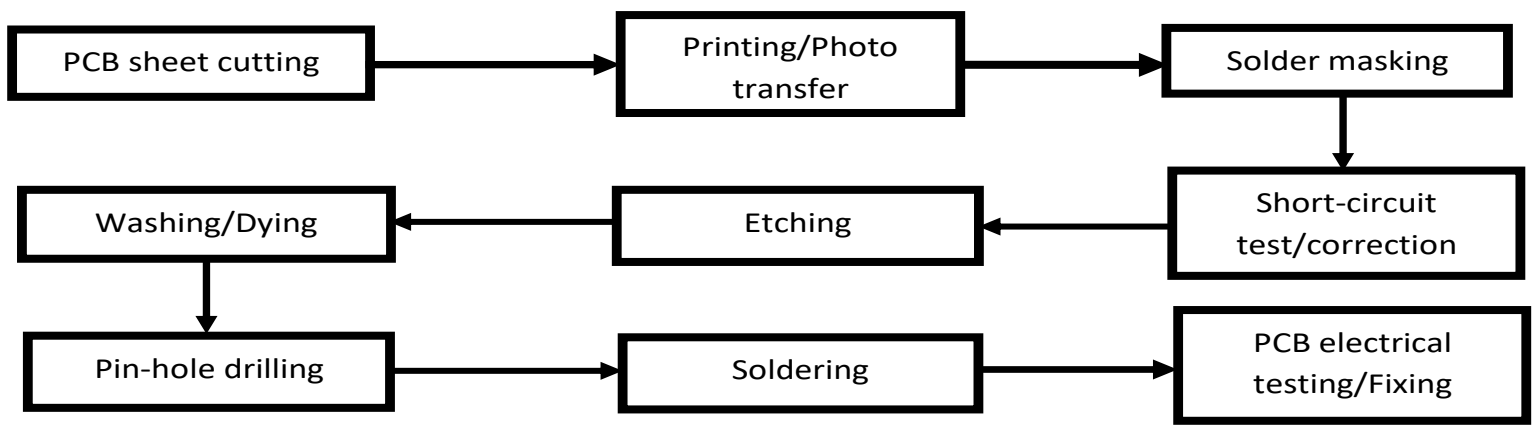

Fig. 10: The block diagram of the PCB design stages 


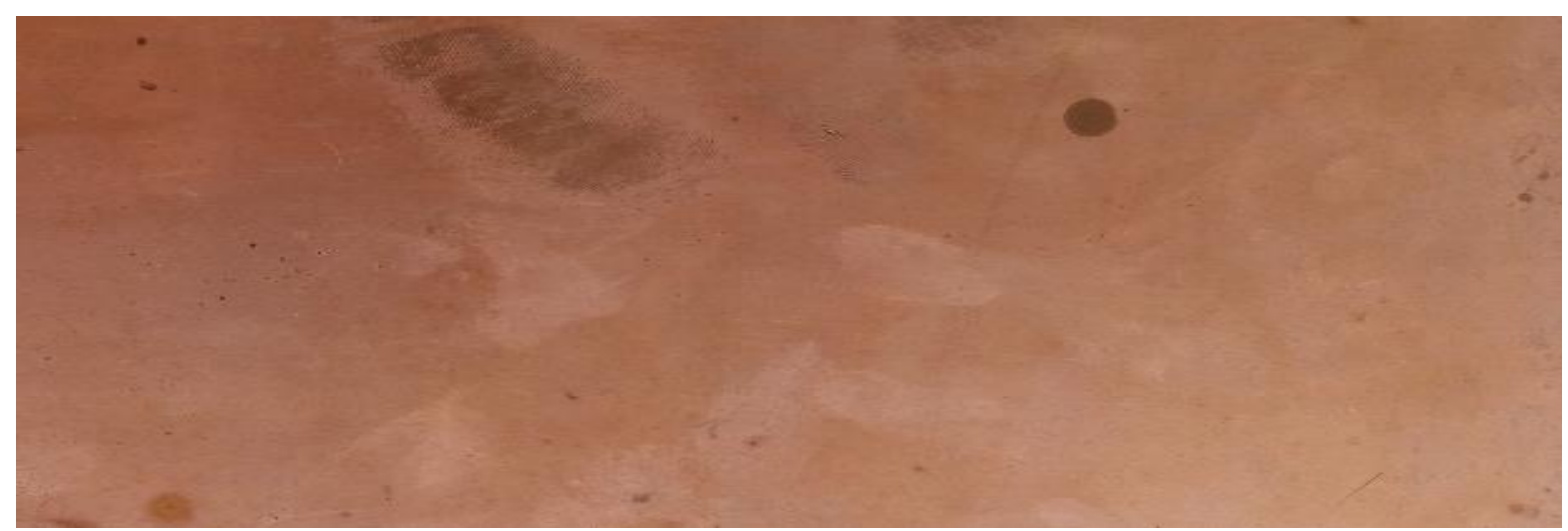

Fig. 11: Front view of the $P C B$ metallic sheet $(5 \mathrm{~cm} * 10 \mathrm{~cm})$

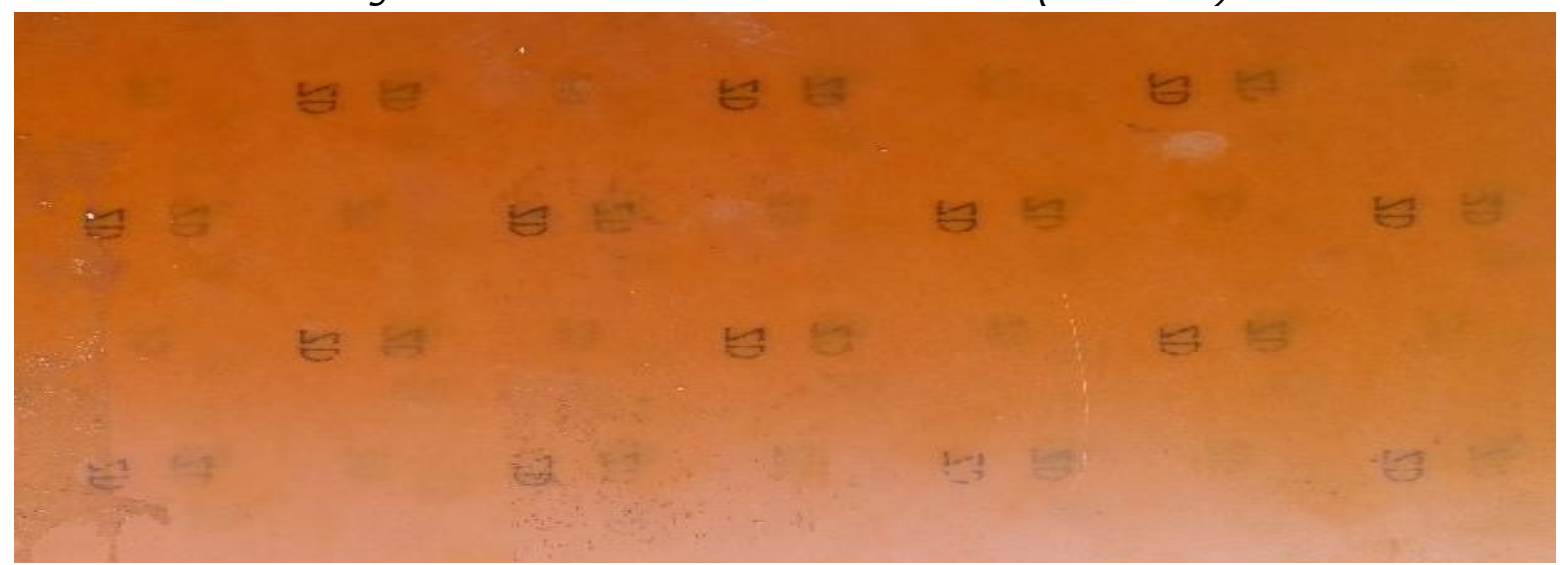

Fig.12: Back view of the $P C B$ metallic sheet $(5 \mathrm{~cm} * 10 \mathrm{~cm})$

\subsection{The Procedures for PCB Etching}

For the etching to be done correctly the underlisted steps must be followed:

i. Provide a PCB metallic plain board and cut out the space circuit board needed.

ii. The printed circuit outline done in MULTISIM 14.0 version was placed vertically on the metallic surface of the cut-out board and glued firmly.

iii. The rear surface was damped with tina fluid to instinct the printed areas to the board.

iv. Leaving for about 20 minutes to dryness, it is then submerged in cold water for about 5 minutes to remove other parts of the unwanted paper.

v. Hole drills were made to the sizes of the respective components pins to be fixed on the surfaces.

vi. The connections on the surface were crosschecked to ensure that no lines were erase by the tina fluid, otherwise there's need to coat the lines with black Cortex and then sundry to about 10 minutes. vii. A 3- 4 spoonful of Ferric Chloride (Iron III Chloride) were added to water in a basin and stir thoroughly.

viii. The prototype was then submerged in the plastic basin containing the solution of (vii) for about 45-60 minutes.

ix. Between this time, the work piece had to be inspected to verify if the unwanted surfaces were attack/removed by the solution.

$\mathrm{x}$. When satisfied, the work piece was then brought out from the solution and submerge in a cold water to rinse the chemical solution therein and thereafter, removed the prototype and clean the surfaces with dry cloth by ensuring that the cortex and unwanted surfaces were off the board.

xi. The surfaces that needed to be of thick lines such as high current/ voltage paths were being thickened by soldering them.

xii. Finally, the components were inserted by the process called insertion to the PCB prototype board and soldered appropriately. 


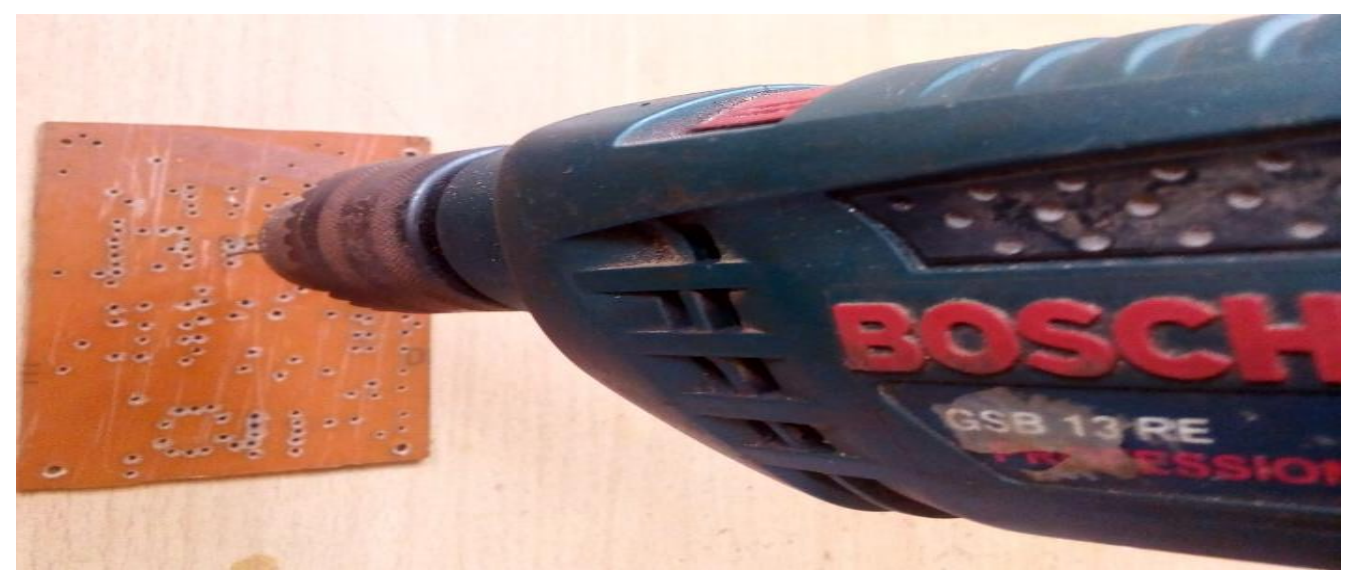

Fig. 13: Pin-hole drilling using drilling machine

\section{RESULTS}

Application of this work can be found in domestic appliance electrical and electronic gadgets, cars, sensors, locks, navigational instruments, surgical instruments, musical instruments etc. Fig. 14 consists of the clean soldered surface of the PCB prototype. Figure 15 represents the positive output of the $+15 \mathrm{~V}$ regulator mounted on PCB at 5VDC per division of the oscilloscope. Figure 16 illustrates the negative output of the $+15 \mathrm{~V}$ regulator mounted on PCB at 5VDC per division of the oscilloscope.

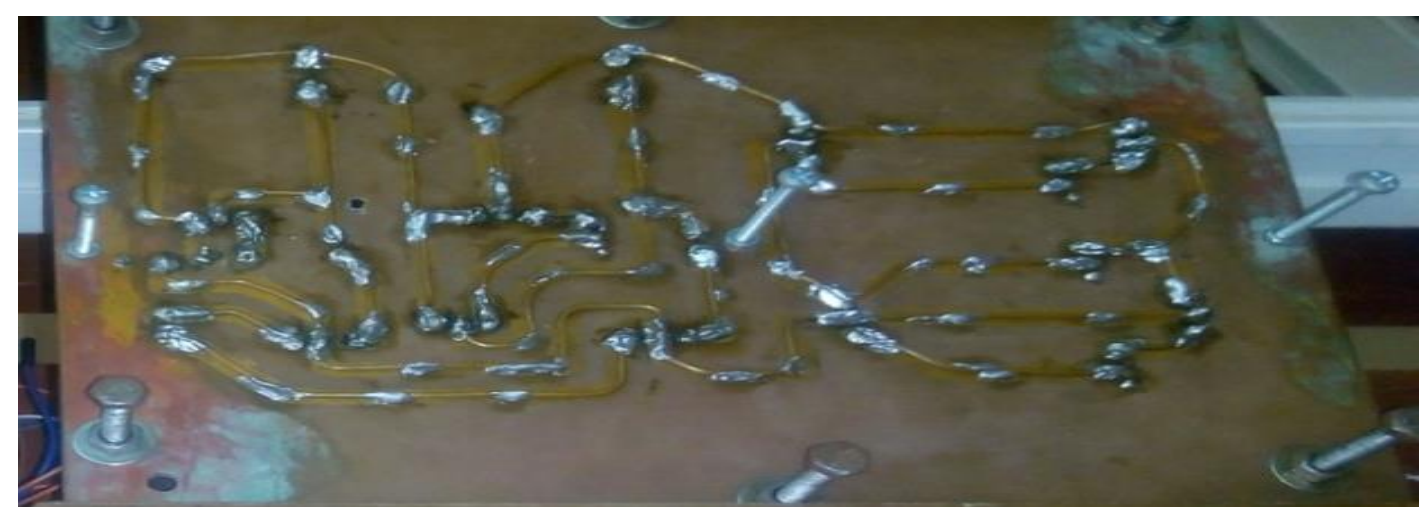

Figure 14: Soldered Surface of the PCB Prototype

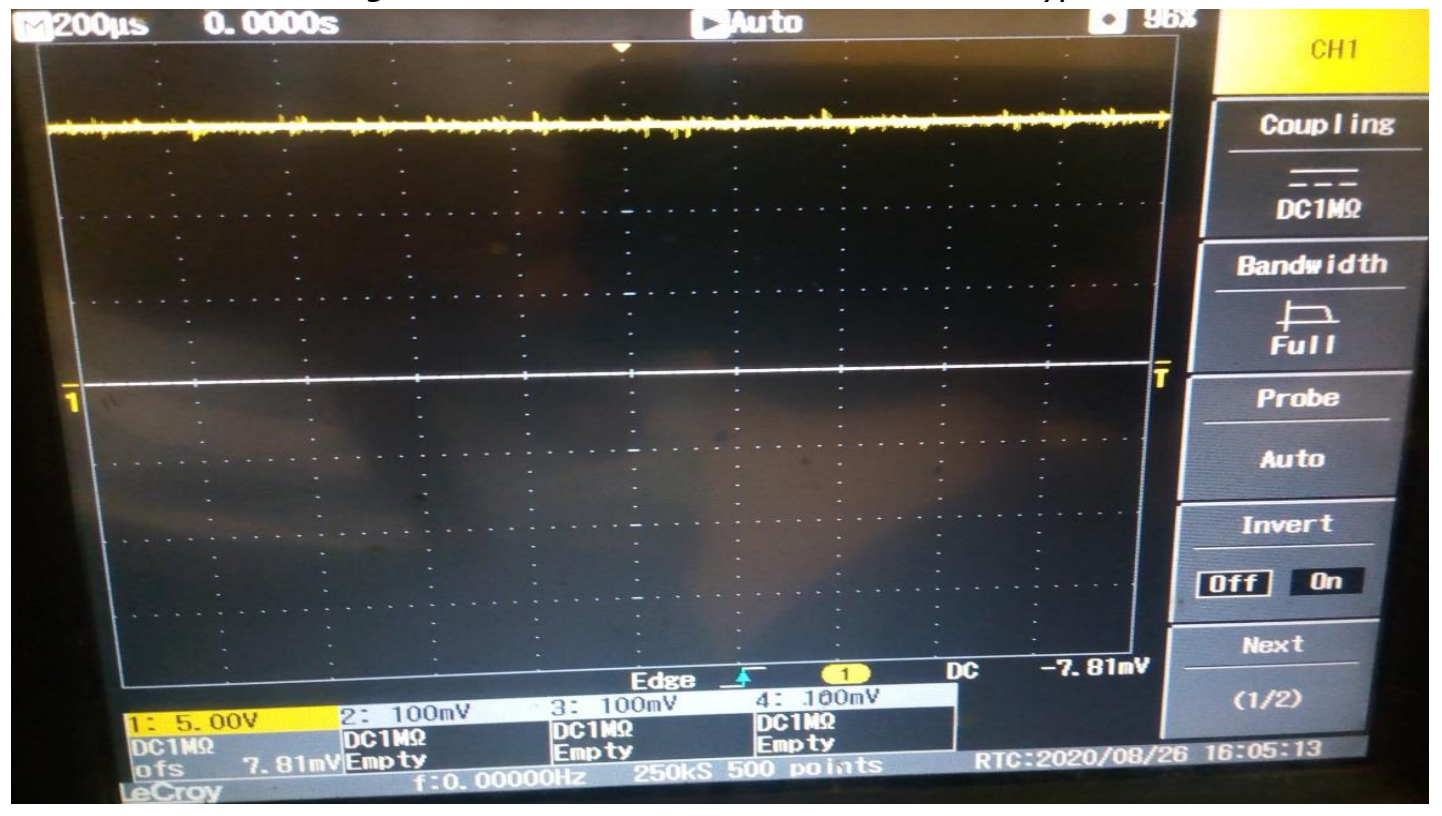

Figure 15: Output voltage test of $+15 \mathrm{v}$ in LeCroy oscilloscope probe 1 


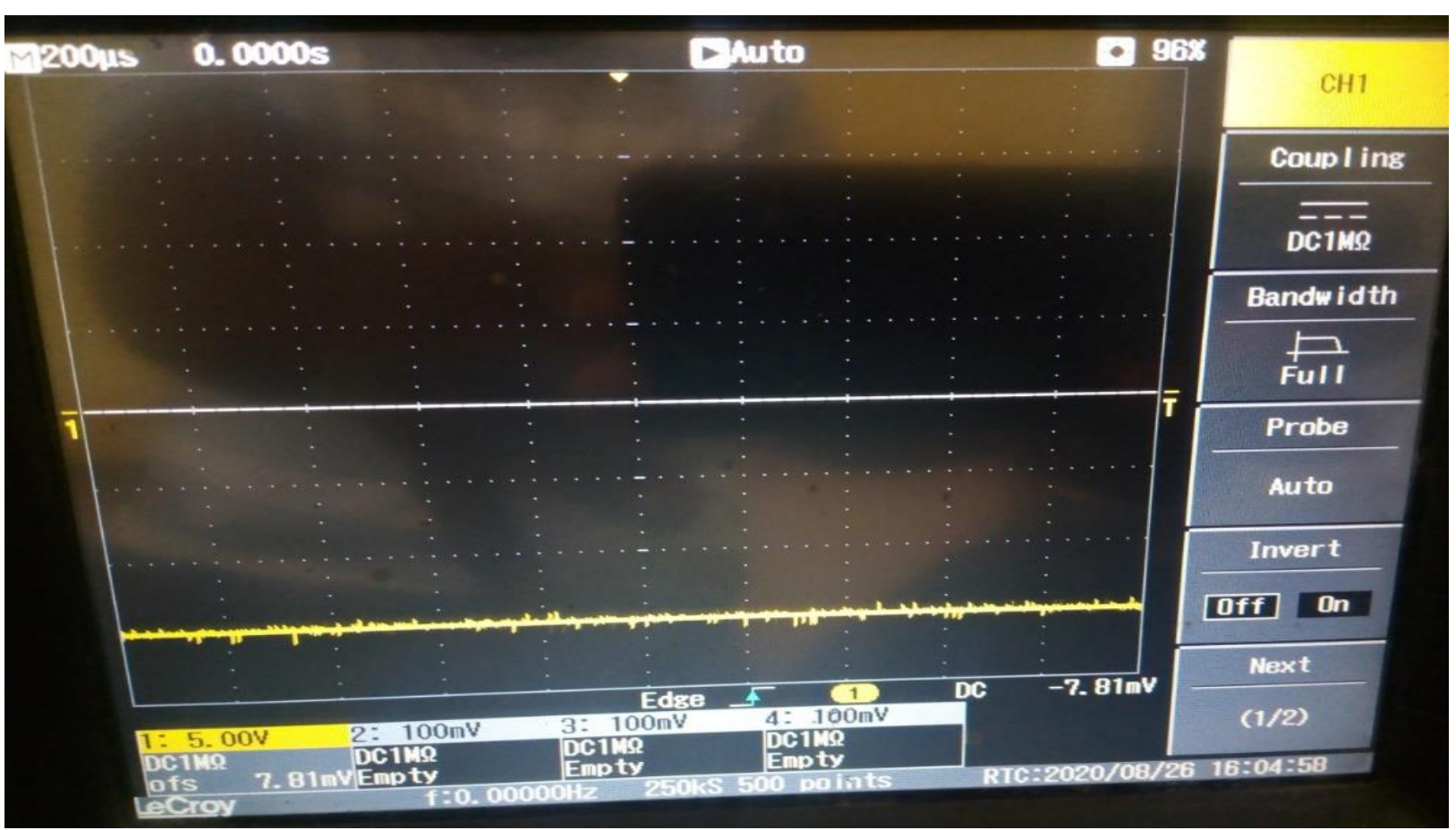

Figure 16: Output voltage test of -15v in LeCroy oscilloscope probe 1

\section{COST COMPARISON}

Table 1 displays the cost analysis of the proposed system based on chloride solution scheme. It is observed that the cost of producing five pieces of PCB using the proposed technique is $\mathrm{N} 1,120.00$. Table 2 shows the comparative analysis of the proposed system with other methods of producing
PCB. It is observed that the cost of producing 5 pieces of PCB using barbones, PCB Express EI and the proposed system are $11,483.158,946.20$ and 1,120 in Naira respectively. Therefore, it is evident that the proposed system in this research work is cheaper than the two other techniques as shown in Table 2.

Table 1: Cost Analysis of the proposed system for production of five PCB

\begin{tabular}{llll}
\hline S/N & Materials & Quantity & Amount(Naira) \\
\hline 1. & Ferric Chloride & 5 spoonfuls & 300.00 \\
2. & PCB Plane Board & 5 pieces $(5 \mathrm{~cm} \times 10 \mathrm{~cm})$ & 600.00 \\
3. & Tina Fluid & 1 bottle & 70.00 \\
4. & Cutex Paint & 1 bottle & 50.00 \\
5. & Art Paper & 5 sheets & 100.00 \\
\hline & Total & & $1,120.00$ \\
\hline
\end{tabular}

Table .2: Comparative Cost Analysis of the proposed systems with other cost of PCB techniques

\begin{tabular}{lllll}
\hline S/N & Type of PCB Production Techniques & $\begin{array}{l}\text { Number of } \\
\text { PCB }\end{array}$ & $\begin{array}{l}\text { Cost per PCB } \\
\text { (Naira) }\end{array}$ & $\begin{array}{l}\text { Total Cost } \\
\text { (Naira) }\end{array}$ \\
\hline 1. & Barbones [8] & 5 pieces & 2296.63 & $11,483.15$ \\
2. & PCB Express EI[8] & 5 pieces & 1789.24 & $8,946.20$ \\
3. & Proposed system Based on chloride & 5 pieces & 224.00 & $1,120.00$ \\
\hline
\end{tabular}




\section{CONCLUSIONS}

Presented here is a low-cost printed circuit board design technique and processes using ferric chloride solution. To overcome the shortcomings arising from loose connections, mechanical insertion of components have to be on stated precisions. Printed Circuit Board Manufacturing Processes of Printed circuit boards (PCBs) were electronic circuits created by mounting electronic components on a nonconductive board, and creating conductive connections between them. Because PCBs were the most essential part in an electronic system, these were employed in the manufacturing of business machines and computers, as well as communication, control, home entertainment equipment, power inverters [6 - 7]. The future direction of this research work should be focused on comparing other methods of assembling the components on circuit boards with PCBs.

\section{REFERENCES}

[1] Khandpur, R. S., "Printed Circuit Boards: Design, Fabrication, Assembly and Testing," McGrawHill, 2005.

[2] Crama, Y., Flippo, O. E., Klundert, J. J. V. D., and Spieksma, F. C. R., "The Assembly of Printed Circuit Boards: A Case with Multiple Machines and Multiple Board Types," European
Journal of Operational Research, Vol. 98, No. 3, pp. 457-472, 1997.

[3] Orosun R. O, Orosun, M. M., Salawu N.B. and Ige, S. O. "PCB Design using Local Technology and Autocad". IOP conference series: Journal of Physics, 1299, 012063, 2019.

[4] Smed, J., Puranen, L. and Nevalainen, "Job Grouping in Surface Mounted Component Printing", Robotics and Computer-Integrated Manufacturing, 15:39-49, 1999.

[5] $\mathrm{H}$ ayrinen, Johnsson, Johtela, Smed, and Nevalainen, "Scheduling Algorithms for Computer-Aided Line Balancing in Printed Circuit Board Assembly', Production Planning \& Control, 11:497-510, 2000.

[6] Omeje, C. O , Nnadi, D. B , Odeh, C. I, Eya, C. $\mathrm{U}$. and Oti S. E, "Analysis of a three phase capacitor voltage balanced hybrid multi-level inverter with a three phase RL-load," International Journal of Engineering \& Technology, Vol (9), pp. 133-148, 2020.

[7] Eya, C.U and M.U Agu, "Solar-based boost differential single phase inverter," Nigerian Journal of Technology, Vol. 34 no. 1, pp. 11158443, 2015.

[8] https://www.seeedstudio.com/blog/2017/05/ $11 /$ pcb-cost-comparison 